\title{
Preparation of hybrid transparent electrodes of silver nanowires and chemically converted graphene on abitrary substrate at low temperature
}

- Hoang Thi Thu

- Huynh Tran My Hoa

- Tran Quang Trung

University of Science, VNU-HCM

(Received on December $04^{\text {th }} 2014$, accepted on September $23^{\text {rd }} 2015$ )

\begin{abstract}
Graphene has been enjoyed significant recent attention due to its potential applications in electronic and optoelectronic devices. Graphene is usually prepared via Hummers' method or modified Hummers' methods. These methods are the most suitable for the large-scale production of single graphene at low cost. But their main drawbacks are the use of strong oxidizing agents which make graphene films separating into small sheets and this extremely decrease the electrical conductivity of graphene. Herein, we report an inexpensive, fast and facile method for preparation of a double layer structured transparent, flexible hybrid electrode from
\end{abstract}

silver nanowires ( $A g N W s$ ) with chemically converted graphene (CCG) coating on arbitrary substrate. These films dramatically decreases the resistance of graphene films and exhibited high optical transmittance (82.4\%) and low sheet resistance (18 $\Omega /$ sq), which is comparable to ITO transparent electrode. The ratio of direct conductivity to optical conductivity $\delta_{D C} / \delta_{O P}=104$ of this electrode is very close to that displayed by commercially available ITO. Especially, the whole fabrication process is carried out at low temperature. The graphene films are spin coated directly on the substrate without transferring therefore eliminating troubles that are brought from the transfer method

Keywords: graphene, silver nanowires, conducting films, hybrid electrodes, low temperature.

\section{INTRODUCTION}

Transparent and conducting metal oxides such as indium tin oxide (ITO) have been widely used as an essential element of various optoelectronic devices such as organic lightemitting diode (OLED) panels, touch screen panels, e-paper, and solar cells. Vacuum deposited ITO transparent electrode possesses good physical properties such as high optical transmittance and low sheet resistance as a transparent electrode for various optoelectronic devices [1]. However, it has several drawbacks such as brittleness and high processing temperature. Furthermore, the scarcity of indium resources makes ITO transparent electrode very expensive recently. Therefore, cheap, flexible, and solution-process able transparent electrodes have been required for the next generation of optoelectronic devices such as flexible solar cells 
and displays. Recently, new transparent electrode materials such as graphene, carbon nanotubes (CNT), and Ag nanowire (Ag NWs) films have been developed to replace the conventional ITO transparent electrode [4-6, 11, 12]. Among various ITO alternatives, $\mathrm{Ag}$ NWs films already showed the good optical and electrical performance comparable to ITO $[9,13,14]$. Ag NWs, prepared by polyol method, are facile and extremely low cost. Additional, Ag NWs films can be fabricated by many methods such as spin coating, bar coatings or spray coating but one of the drawbacks of Ag NWs films is that it can be easily oxidized when being exposed to ambient condition for a long time. Therefore, thermal oxidation stability of the Ag NWs films is much poorer than the competing transparent conductors such as CNT and graphene with theoretical values of charge carrier mobility higher than $200000 \mathrm{~cm}^{2} / \mathrm{V}$ and single layer graphene only absorbs about $2.3 \%$ of visible light. Although the CVD grown graphene has been used in various application areas, we should address some obstacles, such as catalyst material, growth conditions, etching problems, transfer technical and the high cost of CVD graphene. Fortunately, CCG is usually prepared by using chemical method that is the most suitable for the largescale production of single graphene at low cost. However, the main drawbacks of these methods are the use of strong oxidizing agents make graphene sheets separating into small pieces (as shown in Fig. 1A) leading to extremely decrease electrical conductivity of graphene films. Fig. 1C also shows many defects in CCG films via Raman spectroscopy. The Raman D band ( 1365 $\mathrm{cm}^{-1}$ ) of graphene is activated by the defects that cause an intervally double resonance involving transitions near two inequivalent $\mathrm{K}$ points at neighboring corners of the first Brillouin zone of graphene [7]. To improve the conductive properties of chemical graphene films the authors have attempted to percolate more and more layers of CCG on the substrates (as shown in Fig. 1B). But this way is not efficient in decreasing the resistance of the electrode $(\mathrm{R}=21000 \Omega / \mathrm{sq}$ with $\mathrm{T}=78.13 \%$ at $550 \mathrm{~nm}$ ). A too high resistance needed to be applied to TCF for photovoltaic to attain the sheet resistances of $10 \Omega / \mathrm{sq}$ to $50 \Omega / \mathrm{sq}$ approximately. Just recently, Iskandar $\mathrm{N}$. Kholmanov et al reported that they had experimentally verified this model by covering Ag NWs with single layer of graphene on glass substrate, and the obtained hybrid film exhibited the lowest sheet resistance of $64 \Omega / \mathrm{sq}(\mathrm{T}=93.6$ $\%)$. Following, Yang Liu et al had also successfully fabricated this model on a flexible substrate with lowest sheet resistance of 32.5 $\Omega / \mathrm{sq} \quad(\mathrm{T}=81.5 \%)$ [15]. Although hybrid transparent electrodes of Ag NWs and graphene are demonstrated in many publication, only few additional attempts toward hybrid with chemical graphene are reported.
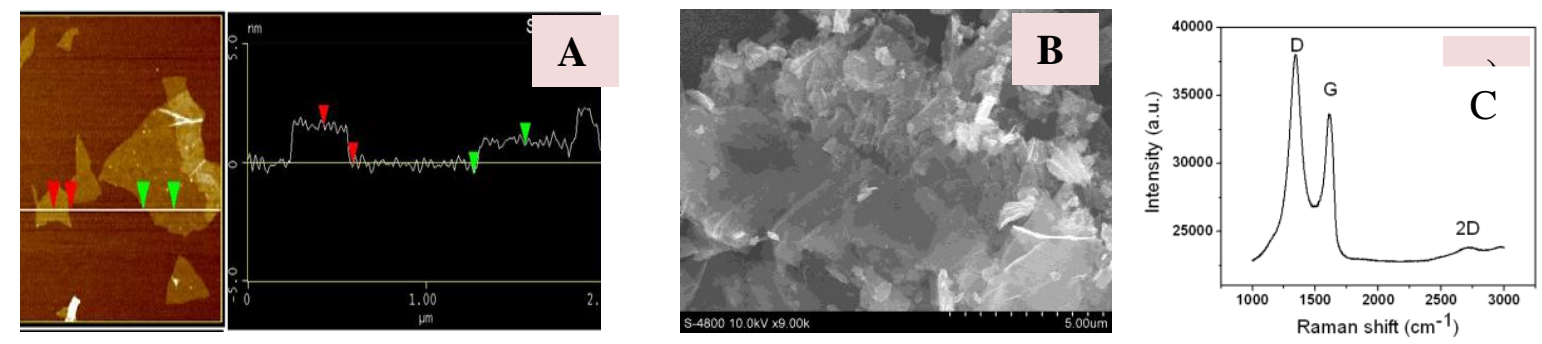

Fig. 1. Characterization of chemical graphene. (A) AFM images of graphene oxide sheets with their height profiles (B) SEM image of many sheets of graphene. (C) Raman spectroscopy of CCG $(1300-1400 \mathrm{~cm})$ centered on the D mode (1365 $\mathrm{cm})$.

\section{Trang 48}


Therefore, in this work we demonstrate here experimentally the assembly of CCG with $1 \mathrm{D} \mathrm{Ag}$ NWs. The benefits of using this hybrid films are not only to connect the CCG islands but also to protect the fiber $\mathrm{Ag}$ from oxidation $[6,8]$. CCG/Ag NWs hybrid films with TCF characteristics can be comparable to that of ITO films (typically, $\mathrm{Rs}=18 \Omega / \mathrm{sq}$ for an optical transmittance at $\lambda=550 \mathrm{~nm} \mathrm{T550}=82.4 \%$ ). The authors have fabricated transparent electrodes at a low temperature by adding Ag NWs to CCG. The hybrid transparent electrodes on plastic films exhibited low sheet resistance, high transparency, and excellent flexibility. These studies on hybrid transparent electrodes demonstrate the potential for the fabrication of electrical devices on plastic films by continuous roll-to-roll processes using a simple, inexpensive, and scalable process. The goal of this study was to fabricate graphene hybrid films with a Ag NWs network on any arbitrary substrate. The process sequence of synthesizing CCG/Ag NWs hybrid films is illustrated in Fig. 2. Ag NWs dispersion in deionized water is being sprayed on a precleaned polyethylene terephthalate (PET) or glass substrate, followed by a spraying process, to form conductive subpercolating network of Ag NWs. Then, several layer graphene films are spin coated on the top of the network of Ag NWs to form the final hybrid transparent electrodes. See experiment section for detailed information.

\section{METHODS}

Synthesis of Ag NWs, GO.

The Ag NWs material was synthesized by polyol method and GO (graphene oxide) material was prepared by modified Hummer method at our laboratory. More details were presented in our previous studies [2, 3].

Optical transparency at the wavelength of $550 \mathrm{~nm}$ was measured using a UVVis spectrophotometer (JASCO Corp., Tokyo, Japan) with a glass or PET substrate as a reference. The morphology of the samples was observed using a scanning electron microscope (SEM) (JSM6700F, JEOL Ltd., Tokyo, Japan) and Atomic force microscope (AFM) (University of Ulsan, Daehak-ro 102, Nam-gu, Ulsan 680-749, South Korea). The sheet resistances of the hybrid films (before and after bending test) were measured using the four-probe method.

\section{Fabrication of hybrid CCG/Ag NWs electrode}

The Ag NWs/CCG hybrid transparent electrode reported herein was fabricated on a glass or PET substrate with two steps. Firstly, Ag NWS is spray coated on the arbitrary substrate to form Ag NWS network. Secondly, GO solution is directly sequential spin coated on the $\mathrm{Ag}$ NWs network. Finally, this hybrid films are exposed to hydrazine and heated to $150{ }^{\circ} \mathrm{C}$ in the air condition to reduce to CCG films. In this report, we fabricated Ag NWS networks on the arbitrary substrates with the same concentration of $\mathrm{Ag}$ NWs and conditional procedure. Through changing the thickness of CCG on the substrate, five samples were obtained and labeled as: H1, $\mathrm{H} 2, \mathrm{H} 3, \mathrm{H} 4$ and $\mathrm{H} 5$. We also prepared 5 samples (only with CCG) with the same thickness corresponding with the thickness of CCG in the samples of hybrid and used as the reference. 


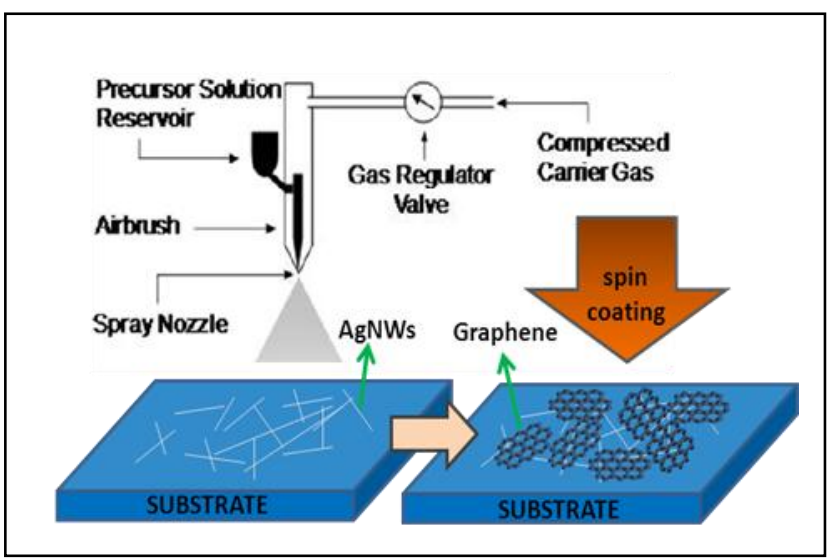

Fig. 2. Fabrication of graphene/Ag NW films. Schematic illustration of hybrid film fabrication.

\section{RESULTS AND DISCUSSION}

The morphology of the as-synthesized $\mathrm{Ag}$ NWs was determined by SEM image (Fig. 3) The Ag NWs is separated, majority with 40-50 $\mathrm{nm}$ diameter and upper $20 \mu \mathrm{m}$ length, and the rest amount of nanoparticles is insignificant [2].

In this proceeding, the improvement of good contact among AgNWs network is extremely important and the annealing temperature is the key for solving this problem. The heat treatment

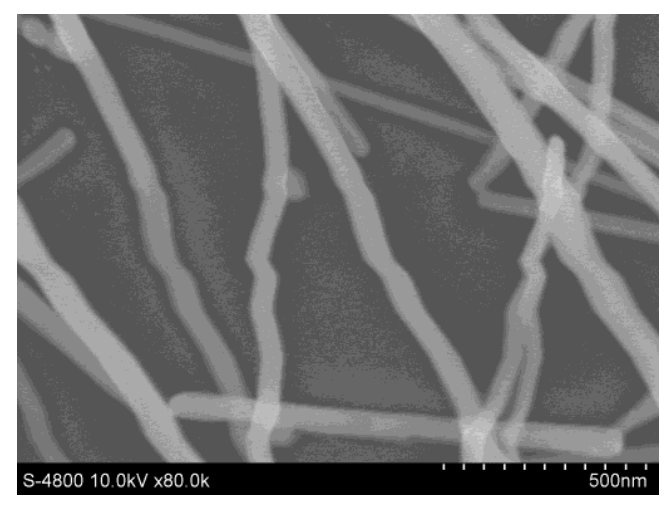

Fig. 3. SEM image of AgNW network not only removed the remained PVP on the surface of the $\mathrm{Ag}$ NWs but also fused the $\mathrm{Ag}$ NWs together. Such that tight connections led to high conductivity.

Fig. 4 showed the SEM image of the Ag NWs-CCG hybrid electrode in which the $\mathrm{Ag}$ NWs create conductive bridges between graphene sheets leading the efficiency in collecting and transporting carriers to the external circuits.

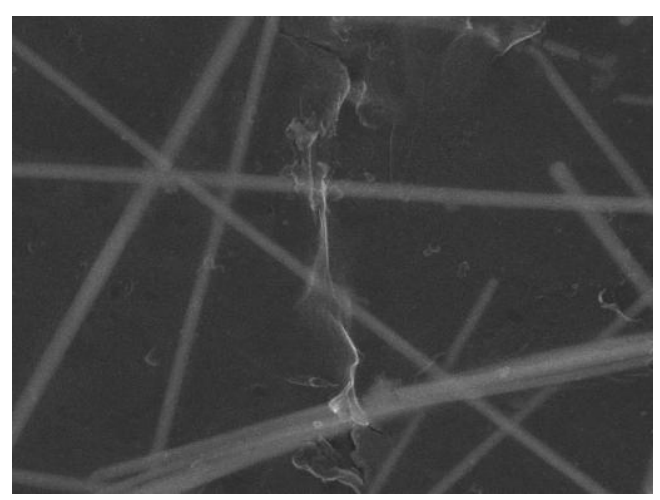

Fig. 4. SEM image of CCG/Ag NWs on glass substrate demonstrate that the Ag NWs bridge line defects and line disruptions (scale $500 \mathrm{~nm}$ ).

\section{Trang 50}


So these hybrid films show resistance 18 $\Omega / \mathrm{sq}$ with $\mathrm{T}=82.4 \%$ at $550 \mathrm{~nm}$ (for glass substrate), while previously resistance of $\mathrm{Ag}$ NWS and graphene is $75 \Omega / \mathrm{sq}$ and $350000 \Omega / \mathrm{sq}$ repectively. This improved the electrical conductivity of the graphene films up to 2000 times. To explain the vast improvement in the sheet resistance of a Ag NWs-CCG electrode, we also agree with the explanation of V.C. that the formation of an extended conjugated network with individual $\mathrm{Ag}$ NWs bridging the gaps between graphene sheets. The large graphene sheets cover the majority of the total surface area, while the Ag NWs act as wires connecting the large pads together [11].

In Fig. 5 and Fig. 6, the optoelectronic performances of the CCG/Ag NWs films and CCG films are further compared. From Fig. 5, the transmittance of $\mathrm{CCG} / \mathrm{Ag}$ NWs films are slightly reduced by $6 \% \sim 9 \%$, which is due to the added layer of Ag NWs. In contrast, from Fig. 5, the

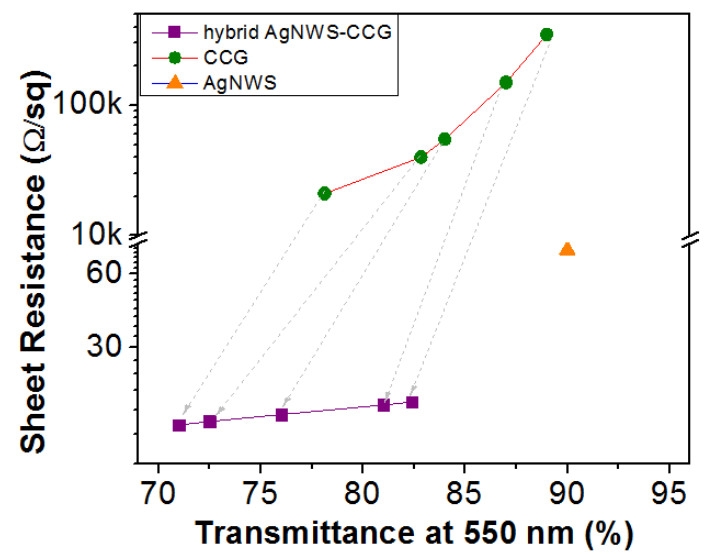

Fig. 5. Sheet resistance vs. transmittance of $\mathrm{Ag}$ NWs, CCG and hybrid CCG/Ag NWs electrode sheet resistance of the obtained hybrid films is simultaneously reduced and even lower than that of Ag NWs film. Therefore, another advantage of the coated Ag NWs can be concluded that it may play a role of increasing the conductivity of graphene film through its unique electronic properties.

Recently, to evaluate optical and electrical properties of the thin films, the concept of aspect ratio $\delta_{\mathrm{DC}} / \delta_{\mathrm{Op}}$ is often used. We conclude that the higher the aspect ratio, the better the properties of TCO thin film. The transmittance and sheet resistance for thin films are related by (1) expression, where $\delta_{\mathrm{Op}}$ is the optical conductivity (here quoted at $550 \mathrm{~nm}$ ) and $\delta_{\mathrm{DC}}$ is the DC conductivity of the film $[9,10]$.

$$
T(\lambda)=\left(1+\frac{188.5}{R_{\mathrm{s}}} \frac{\sigma_{\mathrm{Op}}(\lambda)}{\sigma_{\mathrm{DC}}}\right)^{-2}
$$

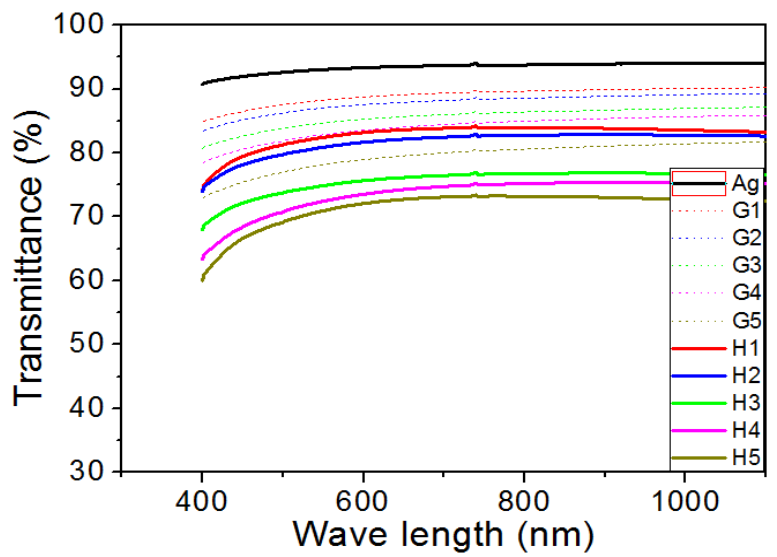

Fig. 6. Transmittance of the AgNWs, CCG and the hybrid CCG/Ag NWs electrode without including the substrate. 
Table 1. The optical and electrical properties of hybrid silver nanowires/graphene film with respect to different molar ratio of CCG and Ag NWs

\begin{tabular}{|c|c|c|c|}
\hline Samples & $\begin{array}{c}\text { Resistance } \\
\Omega / \mathrm{sq}\end{array}$ & $\begin{array}{c}\text { Transmitta } \\
\text { nce } \%\end{array}$ & $\sigma_{\mathrm{DC}} / \sigma_{\mathrm{OP}}$ \\
\hline $\mathrm{Ag}$ & 75 & 90 & 46 \\
\hline Graphene 1 & 350000 & 89 & 0.009 \\
\hline Hybrid 1 & 18 & 82.4 & 104 \\
\hline Graphene 2 & 150000 & 87 & 0.017 \\
\hline Hybrid 2 & 17.5 & 81 & 97 \\
\hline Graphene 3 & 55000 & 84 & 0.038 \\
\hline Hybrid 3 & 16 & 76 & 80 \\
\hline Graphene 4 & 40000 & 82.84 & 0.048 \\
\hline Hybrid 4 & 15 & 72.5 & 72 \\
\hline Graphene 5 & 21000 & 78.13 & 0.069 \\
\hline Hybrid 5 & 14.5 & 71 & 69.6 \\
\hline
\end{tabular}

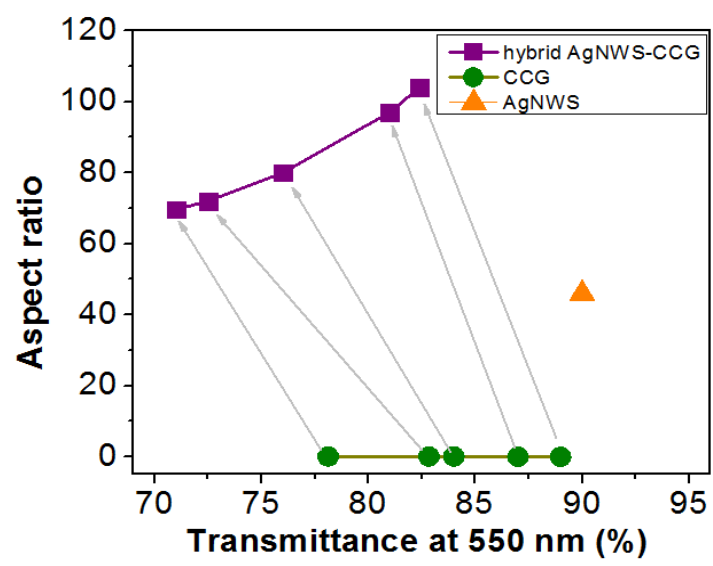

Fig. 7. Comparison of $\sigma_{\mathrm{DC}} / \sigma_{\mathrm{Op}}$ between Ag NWs and graphene/Ag NWs electrode.

\section{CONCLUSION}

In this work, we report an inexpensive, fast and facile method to fabricate a flexible hybrid electrode from silver nanowires (Ag NWs) with CCG coating on an arbitrary substrate. These films significantly decrease the resistance of the bare CCG films and exhibited high optical transmittance $(82.4 \%)$ and low sheet resistance (18 $\left.\Omega \mathrm{sq}^{-1}\right)$. Their ratio of direct conductivity to optical conductivity, $\delta_{\mathrm{DC}} / \delta_{\mathrm{OP}}$, is of 104 at molar ratio of $2: 1$ and at $170{ }^{\circ} \mathrm{C}$ annealing temperature. This condition is very close to that displayed TCO by commercially available ITO. Especially, the whole fabrication process is carried out at low temperature. The graphene films is spin coated directly on the substrate without transferring, therefore eliminating many troubles bring back from transfer method.

\section{Trang 52}




\section{Chế tạo điê̂n cực dẫn điện trong suốt dựa trên tổ hợp lai bạc nanowire và graphene ở nhiệt độ thấp}

- Hoàng Thị Thu

- Huỳnh Trần Mỹ Hòa

- Trần Quang Trung

Trường Đại học Khoa học Tự nhiên, ĐHQG-HCM

\section{TÓM TÁT}

Gần đây, graphene đang rất được chú ý do các ứng dụng tiềm năng của nó trong các thiết bị điện tử và quang điện tử. Graphene thường được chế tạo bằng phương pháp Hummer hoặc Hummer' cải tiến. Các phương pháp này rất thích hợp cho việc sản xuất quy mô lớn với chi phí thấp nhưng những nhược điểm chính của phương pháp này là việc sử dụng các tác nhân oxy hóa mạnh sẽ làm cho màng graphene bị nát, dẫn đến giảm đáng kể tính dẫn điện của màng. Trong bài báo này, chúng tôi trình bày một phương pháp rẻ tiền, nhanh chóng và đơn

\section{TÀI LIẸU THAM KHẢO}

[1]. C.H. Chung, T.B. Song, B. Bob, R. Zhu, Y. Yang. Solution-processed flexible transparent conductors composed of silver nanowire networks embedded in indium tin oxide nanoparticle matrices, Springer. Nano Res, ISSN 1998-0124 (2012).

[2]. H.T. Thu, T.Q. Trung, Preparation of silver nanowires by polyol method and their application for transparent conducting electrode, Sci. Tech, 50/1B, 472-480 (2012).

[3]. T.Q. Trung, L.T. Lua, T.V. Tam, N.T. P. Thanh, H.T. Phong, H.T.M. Hoa, The effect of annealing temperature on conductivity of reduced graphene oxide prepared by the modified hummers method, Journal of

giản để chế tạo điện cực lai dựa trên các dây nano bạc (Ag NWS) với graphene (CCG) trên các đế tùy ý. Những điện cực này có điện trở thấp $(18 \Omega / s q)$ và độ truyền qua cao (82,4\%), có thể so sánh với điện cực trong suốt ITO. Điện cực chế tạo được có tỉ số $\delta_{D C} / \delta_{O P}=104$, gần bằng với đế ITO thương mại. Đặc biệt, toàn bộ quá trình chế tạo được thực hiện ở nhiệt độ thấp. Các màng graphene được quay phủ trực tiếp trên bề mặt đế mà không cần transfer, tránh được rất nhiều khó khăn, hệ lụy do phương pháp này mang lại.

Science and Technology, 50, 1B, 425-431 (2012).

[4]. D.S. Hecht, L.H.G. Irvin, Emerging transparent electrodes based on thin films of carbon nanotubes, graphene, and metallic nanostructures, Advanced Materials, 23, 1482-1513 (2011).

[5]. T. Tokuno, M. Nogi, J. Jiu, K. Suganuma, Hybrid transparent electrodes of silver nanowires and carbon nanotubes: a low temperature solution process, Nanoscale Research Letters, 7, 1, 281 (2012).

[6]. A.Y. Jeong, Y.Y. Lee, Improved thermal oxidation stability of solution-processable silver nanowire transparent electrode by 
reduced graphene oxide, $4,12,6410-4$ (2012).

[7]. I.N. Kholmanov, C.W. Magnuson, A.E. Aliev, R.S. Ruoff, Improved electrical conductivity of graphene films integrated with metal nanowires, Nano Lett., 12, 11, 5679-5683 (2012).

[8]. Y.S. Yun, D.H. Kim, B. Kim, H.H. Park, H.J. Jin, Transparent conducting films based on graphene oxide/silver nano wire hybrids with high flexibility, Synthetic Metals, 162, 15-16, 1364-1368 (2012).

[9]. S. De, T.M. Higgins, P.E. Lyons, E.M. Doherty, P.N. Nirmalraj, W. Blau, J.J. Boland, J.N. Coleman, Silver nanowire networks as flexible, transparent, conducting films: Extremely high DC to optical conductivity ratios, ACS Nano. 3, 7, 1767 1774 (2009).

[10].M. Dressel, G.G. Runer, Electrodynamics of solids: Optical properties of electrons in matter; Cambridge University. Cambridge (2002).
[11].V.C. Tung, L.M. Chen, M.J. Allen, J.K. Wassei. Low-temperature solution processing of graphene-carbon nanotube hybrid materials for high-performance transparent conductors, Nano Lett. 9 (5), 1949-1955(2009).

[12].X.L. Li, G.Y. Zhang, X.D. Bai, X.M. Sun, Wang, X.R. Wang, E. Dai, H.J. Nat, Highly conducting graphene sheets and LangmuirBlodgett films, Nanotechnol, 3, 538 (2008).

[13].E.C. Garnett, L. Mark. Brongersma, Self Limited plasmonic welding of silver nanowire junctions, Nature Materials, 11, 241-249 (2012).

[14].L.Yang, T. Zhang, W. You, Solution Processed flexible polymer solar cell with silver nanowire electrodes, ACS Applied Materials and Interfaces, 3, 4075-4084 (2011).

[15].Y. Liu, Q. Chang, L. Huang, Transparent, flexible conducting graphene hybrid films with a subpercolating network of silver nanowires, J. Mater. Chem. C, 1, 2970-2974 (2013).

\section{Trang 54}

